\title{
Chest CT Findings in EBUS-TBNA-Proven Anthracosis in Enlarged Mediastinal Lymph Nodes
}

\section{Mittels EBUS-TBNA gesicherte Anthrakose in vergrößerten mediastinalen Lymphknoten: Computertomografischer Befund}

Authors

Affiliations
J. Kirchner ${ }^{1}$, P. Mueller², M. Broll ${ }^{3}$, E. M. Kirchner ${ }^{3}$, N. Pomjanski ${ }^{4}$, D. Liermann ${ }^{5}$, S. Biesterfeld ${ }^{4}$, R. Kickuth ${ }^{6}$

Affiliation addresses are listed at the end of the article.

\author{
Key words \\ - EBUS-TBNA \\ - computed tomography \\ - mediastinum \\ - lymph node \\ - anthracosis \\ - sarcoidosis \\ - lymphadenopathy \\ - occupational/environmental \\ hazards
}

\section{Zusammenfassung \\ V}

Ziel: Darstellung computertomografischer Befunde von mittels endobronchialer ultraschallgesteuerter Nadelbiopsie (EBUS-TBNA) gesicherten Fällen vergrößerter hilärer und mediastinaler Lymphknoten mit Zeichen der Anthrakose.

Material und Methoden: Es erfolgte eine retrospektive Auswertung der MSCT von 39 Patienten (28 männlich, 11 weiblich) mit EBUS-TBNA gesicherter Diagnose von 53 vergrößerten anthrakotischen Lymphknoten.

Ergebnisse: Die durchschnittliche Länge der Kurzachse der erfassten Lymphknoten betrug $13,7 \mathrm{~mm}$. Die anthrakotischen Lymphknoten wiesen am häufigsten eine ovale Form (84\%) auf und waren meistens scharf begrenzt (66\%). 32\% der anthrakotischen Lymphknoten waren allerdings mit umliegenden Lymphknoten verbacken. Anthrakotische Lymphknoten zeigen relativ häufig Verkalkungen (24,5\%). Kontrastmittelanreicherungen (3,8\%) oder zentrale Hypodensitäten als Zeichen der fettigen Degenerierung $(3,8 \%)$ wurden nur in einzelnen Lymphknoten nachgewiesen. Lymphknoteneinschmelzungen wurden nicht beobachtet.

Schlußfolgerung: Die Lymphknotenanthrakose findet sich am häufigsten in scharf begrenzten ovalären mediastinalen Lymphknoten, kann jedoch relativ häufig auch in konfluierenden und Verkalkungen aufweisenden, vergrößerten mediastinalen Lymphknoten gefunden werden.

\section{Introduction \\ Introduction}

Herr Prof. Johannes Kirchner
Radiologie, Allgemeines
Krankenhaus Hagen
Grünstraße 35
58095 Hagen
Germany
Tel.: ++ 49/0 23 31/2 01/23 74/
-23 73
Fax: ++49/0 23 31/2 01/23 65
kirchner@akh-hagen.de

Anthracosis is a form of pneumoconiosis, which is not only caused by coal dust, but also other environmental factors such as air pollution, biomass fuels used extensively for cooking ("hut lung"), and cigarette smoking [1-5]. Thus, it is not a disease per se and may occur in many different conditions and diseases. Since anthracosis

\section{Abstract \\ $\nabla$}

Purpose: We demonstrate the multislice computed tomography (MSCT) findings of endobronchial ultrasound-guided transbronchial needle aspiration (EBUS-TBNA)-proven hilar and mediastinal lymph node enlargement with signs of anthracosis.

Materials and Methods: 53 enlarged lymph nodes in 39 patients (28 male, 11 female) with EBUSTBNA-confirmed anthracosis were analyzed retrospectively.

Results: The mean short axis diameter of the enlarged lymph nodes with signs of anthracosis was $13.7 \mathrm{~mm}$. Lymph nodes most often showed an oval shape $(84 \%)$ and were well defined in $66 \%$ of cases. Lymph node confluence was observed in $32 \%$ of cases. Calcifications were documented in $24.5 \%$ of cases. Contrast enhancement and fatty involution were seen seldom (3.8\%). Lymph node necrosis was not seen.

Conclusion: Lymph node anthracosis may be found most often in enlarged, well defined lymph nodes with an oval shape, frequently associated with confluence and calcifications.

Citation Format:

- Kirchner J, Mueller P, Broll M etal. Chest CT Findings in EBUS-TBNA-Proven Anthracosis in Enlarged Mediastinal Lymph Nodes. Fortschr Röntgenstr 2014; 186: 1122-1126 not only causes alterations of the lung parenchyma, but also of the lymph nodes [6], radiologists should be aware of pathological findings in mediastinal lymph nodes also in this condition.

The aim of this comparative study of EBUS-TBNA and chest computed tomography (CT) was to demonstrate the findings in enlarged mediastinal lymph nodes with signs of anthracosis. 


\section{Material and methods}

\section{$\nabla$}

We performed a retrospective study on all patients of our institutions showing enlarged hilar or mediastinal lymph nodes on CT in which EBUS-TBNA confirmed the diagnosis of lymph node anthracosis. The period of patient recruitment was April 2009 to April 2012.

Multidetector CT examinations (MSCT) were carried out using a Siemens Somatom 64 (Siemens Medical Solutions, Forchheim, Germany) or a Toshiba Aquilion 64 (Toshiba Medical Systems, Tokyo, Japan) CT system. Images were obtained at full inspiration using a $64 \times 0.75 \mathrm{~mm}$ slice collimation with a tube voltage of $120 \mathrm{kV}$. The tube current (mA) was adjusted in relation to patient attenuation by means of the Care Dose ${ }^{\circledR}$ modus (Siemens Medical Solutions) or the Sure Exposure ${ }^{\circledR}$ modus (Toshiba Medical Systems). The reconstruction slice thickness was $3-5 \mathrm{~mm}$. During MDCT $100-120 \mathrm{ml}$ of $300 \mathrm{mg}$ or $400 \mathrm{mgI} / \mathrm{l}$ contrast medium were generally administered intravenously at a rate of $2-3 \mathrm{ml} / \mathrm{s}$ with a power injector followed by a normal saline "chaser".

Retrospective evaluation of computed tomographic examinations was performed consensually by two board certified radiologists (JK, RK). Mediastinal and hilar lymph node evaluation comprised measurement of size (short axis and long axis). In this setting, lymph node enlargement was defined as showing a size of more than 7-11 mm on the short axis depending on the regional nodal station following Glazer et al. [7]. Enlarged lymph nodes were assessed for density (prevalence of calcification or central low density as a sign of fatty involution), shape (oval, round) and contour (sharp, ill-defined). The presence of lymph node necrosis and noticeable contrast enhancement was documented. Nodal necrosis was considered present when an enlarged lymph node showed ill-defined low-attenuation areas [8]. Noticeable lymph node enhancement was determined as nodal density $>60 \mathrm{HU}$ in CT. The site of the enlarged lymph nodes was documented on a standardized protocol according to the regional lymph node classification of the American Thoracic Society [9]. The evaluation comprised a correlation of CT findings and EBUS reports. In this context, a determination which lymph nodes in CT had been aspirated by TBNA had been performed.

\section{EBUS-TBNA}

Endobronchial ultrasound-guided transbronchial needle aspiration (EBUS-TBNA) was performed with the patient under sedation or under general anesthesia as previously described [10]. A linear array 7.5 MHz ultrasonic bronchoscope (CP EBUS, Olympus Medical Systems, Tokyo, Japan) with a $90^{\circ}$ angle of view was introduced orally or through an intubation tube. After ultrasound identification of a suspicious lymph node, transbronchial needle aspiration was performed using a 22G needle (model NA 201 SX 402, Olympus Medical Systems, Tokyo, Japan) under real-time ultrasound guidance. The aspirated material was prepared on glass slides, air-dried and stained.

We retrospectively evaluated the patients' medical reports and computed tomographic examinations with special regard to the underlying illnesses (diagnosis at admission and discharge), the presence of COPD and emphysema, the smoking status or occupational dust exposure as well as definitive pathologic findings. The nicotine dependence degree was estimated by the consumption of cigarettes throughout life (number of pack-years). Patients were classified as non-smokers, having moderate $(<20$ packyears) or severe dependence (>20 pack-years).
The thickening of bronchial walls as a sign of chronic bronchitis was classified as moderate or severe compared with the representative HRCT images of airway wall thickness as published by Awadh et al. [11]. Vascular attenuation (thinning of pulmonary vessels and reduction in their number) and distortion (increased branching angle or straightening) were considered as signs of emphysema. The severity of emphysema was classified semiquantitatively as mild, moderate or severe.

Descriptive data were presented as means with ranges, if appropriate; categorical data were given as counts and percentages. We correlated the different CT findings as lymph node size, shape, contour, etc. with the clinical conditions performing rank correlation by means of a specialized computer algorithm (MedCalc ${ }^{\circledR}$ Software, Mariakerke, Belgium). The local significance level is set to 0.05 . An adjustment to multiplicity is not performed. Therefore, an overall significance level is not determined and cannot be calculated. The presented findings may be used to generate new hypotheses.

The study was approved by the ethics committee of our university and was compliant with the "Health Insurance Portability and Accountability Act of 1996" (HIPAA). Patient informed consent was not deemed necessary by the ethics committee.

\section{Results \\ $\nabla$}

In 39 retrospectively enrolled patients, cytologically confirmed anthracosis ( $\bullet$ Fig. 1) was diagnosed in 53 lymph nodes. These patients showed a mean age of 65.1 years (range $19-88$ years) with a predominance of the male gender (28/39, $71.8 \%$ ).

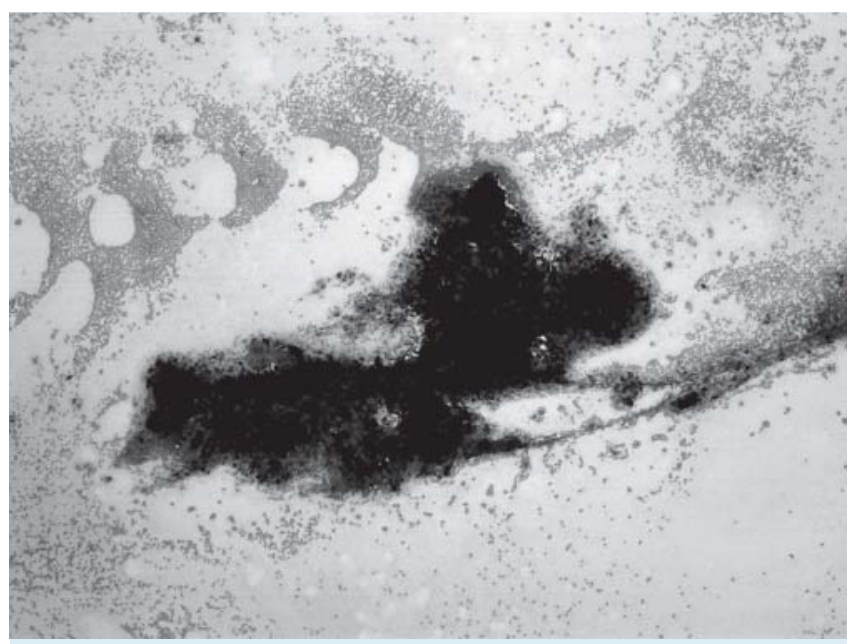

Fig. 1 EBUS-TBNA in lymph node anthracosis: Cytologic specimen of a lymph node fragment with deposition of anthracotic pigment in macrophages and in the extracellular space. At the periphery of the microphotograph, erythrocytes, some inflammatory cells and some normal epithelial cells are present. Papanicolaou staining, $2.5 \times 2$.

Abb. 1 EBUS-TBNA bei Lymphknotenanthrakose: Zytologisches Präparat von Lymphknotenfragmenten mit deutlich erkennbarer Ansammlung anthrakotischen Pigments sowohl im Extrazellularraum als auch in einzelnen Makrophagen. Am Rande des Gesichtsfeldes sind neben Erythrozyten und vereinzelten Entzündungszellen auch Epithelien zu erkennen. Färbung nach Papanicolaou. 2,5×2. 


\section{Clinical conditions}

The retrospective analysis of the electronic health records of these patients yielded that 7 patients had accompanying malignancy ( 5 cases of bronchial cancer, 2 cases of NHL). Slightly more than half of our patients were smokers (22/39, 56.4\%). Moderate nicotine abuse was documented in 15 (38.5\%) patients and severe nicotine abuse in 7 (17.9\%) patients. Only one patient had occupational exposure to dust.

The vast majority of our patients (32/39, 82.1\%) showed thickening of the bronchial walls as a sign of chronic bronchitis. This finding was classified as moderate in 18 cases (46.2\%) and severe in 14 cases (35.9\%). Mild emphysema was seen in 16 patients (41.0\%), moderate emphysema in $5(12.8 \%)$ and severe emphysema in 2 patients $(5.1 \%)$.

Distribution of the examined lymph nodes (o Table 1) Comparing the distribution of EBUS-confirmed enlarged lymph nodes in the ATS regions, we found that the most common site of anthracotic lymph nodes was ATS region 7 (in total 22 nodes, i. e. $41.5 \%$ ). On closer inspection of the other regions, an accumulation of anthracotic lymph nodes was seen on the right side $(2 \mathrm{R}$, $4 R, 10 R, 11 R)$. In these regions $26 / 53$ (49.1\%) of all enlarged nodes with signs of anthracosis were found.

\section{CT findings of enlarged lymph nodes (o Table 2)}

The short axis of the histologically proven enlarged anthracotic lymph nodes ranged from $8 \mathrm{~mm}-23 \mathrm{~mm}$ with a mean diameter

Table. 1 Distribution of the EBUS-confirmed anthracotic lymph nodes with respect to the ATS regions. The most common site was ATS region 7.

\begin{tabular}{|c|c|c|}
\hline ATS region & total & (\%) \\
\hline $2 R$ & 3 & 5.7 \\
\hline $2 \mathrm{~L}$ & 1 & 1.9 \\
\hline $4 R$ & 4 & 7.5 \\
\hline $4 \mathrm{~L}$ & 4 & 7.5 \\
\hline 7 & 22 & 41.5 \\
\hline $10 R$ & 9 & 17 \\
\hline $10 \mathrm{~L}$ & 1 & 1.9 \\
\hline $11 \mathrm{R}$ & 9 & 17 \\
\hline $11 \mathrm{~L}$ & 0 & 0 \\
\hline total & 53 & 100 \\
\hline
\end{tabular}

Table 2 CT findings in enlarged lymph nodes with signs of anthracosis: anthracotic lymph nodes often show an oval shape, well defined margins and demonstrate hyperdensities like small calcifications.

\begin{tabular}{|lllc|}
\hline \multirow{2}{*}{ size } & short axis & $13.7 \mathrm{~mm}$ & \\
\cline { 2 - 4 } & long axis & $19.3 \mathrm{~mm}$ & \\
\hline \multirow{3}{*}{ shape } & \multicolumn{1}{c}{$\%$} & $\mathbf{n}$ \\
& oval & 84.9 & 45 \\
\cline { 2 - 4 } & round & 15.1 & 5 \\
\cline { 2 - 4 } margin & polycyclic & 5.7 & 3 \\
& ill defined & 1.9 & 1 \\
\cline { 2 - 4 } & well defined & 66.0 & 35 \\
\cline { 2 - 4 } & confluence & 32.1 & 17 \\
\hline contrast enhancem & t & 3.8 & 2 \\
\hline calcification & & 24.5 & 13 \\
\hline fat & 3.8 & 2 \\
\hline colliquation & 0 & 0 \\
\hline total & & 53 \\
\hline
\end{tabular}

of $13.7 \mathrm{~mm}$. The long axis ranged from $12 \mathrm{~mm}-31 \mathrm{~mm}$ with a mean diameter of $19.3 \mathrm{~mm}$. The majority of these lymph nodes $(45 / 53$, i.e. $84.9 \%)$ showed an oval shape (@ Fig. 2 ). Only five nodes were round-shaped (15.1\%), and three nodes $(5.7 \%)$ showed a polycyclic shape ( $\odot$ Fig. 3). Confluence of two or more enlarged lymph nodes ( $\bullet$ Fig. 4 ) was seen in $17 / 53$ (32.1\%). Calcification-like hyperdensities were documented in 13 of the examined lymph nodes $(24.5 \%)$. These calcifications were sometimes subtle and spotted, but also diffuse and homogenous (0 Fig. 5 ). Contrast enhancement was documented in 2/53 (3.8\%). Central hypodensity due to fatty involution was seen in two of the anthracotic lymph nodes (3.8\%). Lymph node necrosis was not seen.

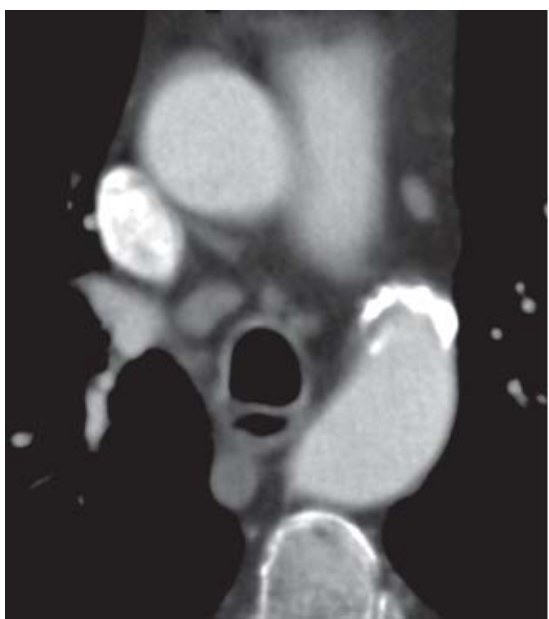

Fig. 2 Chest CT (MSCT $64 \times 0.75 \mathrm{~mm}$ slice collimation, tube voltage $120 \mathrm{kV}$, axial reconstruction) shows a moderately enlarged $(10 \times 20 \mathrm{~mm})$ well-defined oval lymph node without hyperdensities in ATS region $2 \mathrm{R}$; EBUS-TBNA revealed deposition of anthracotic pigment.

Abb. 2 EBUS-TBNA gesicherte mediastinale Lymphknotenanthrakose; die computertomografische Untersuchung (MSCT $64 \times 0,75$ mm Kollimation, Röhrenspannung $120 \mathrm{kV}$, axiale Rekonstruktion) zeigt einen mäßig vergrößerten, scharf abgrenzbaren, ovalären Lymphknoten der ATS-Region $2 \mathrm{R}$.

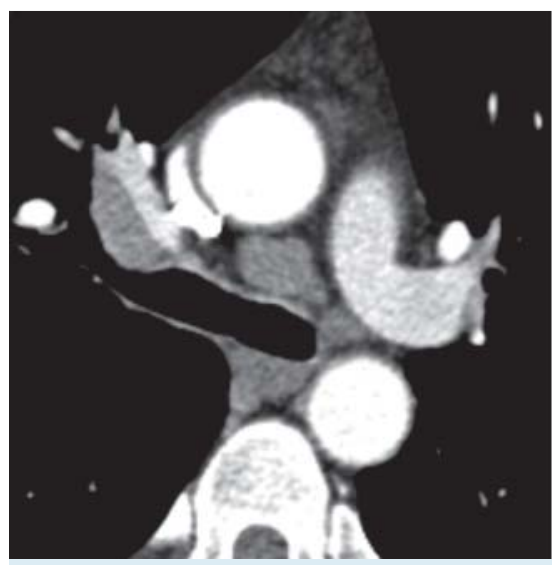

Fig. 3 Distinctly enlarged, well-defined lymph node with EBUS-TBNAconfirmed anthracosis in ATS region $10 \mathrm{~L}$ demonstrating incipient polycyclic shape.

Abb. 3 Deutlich vergrößerter, scharf abgrenzbarer, angedeutet polyzyklisch konfigurierter Lymphknoten der ATS-Region $10 \mathrm{~L}$ (zytologisch Lymphknotenanthrakose). 


\section{Correlation between CT findings and clinical conditions (॰ Table 3)}

We compared clinical characteristics and the most frequent CT findings in enlarged anthracotic lymph nodes. Neither the male gender nor smoking history nor emphysema was correlated with any CT finding of enlarged anthracotic lymph nodes. If at all, only two findings showed correlations with clinical conditions: Calcifications of enlarged anthracotic lymph nodes seemed to be more often present in older patients. Moreover, we found an association between the CT finding of lymph node confluence and a higher degree of chronic bronchitis.

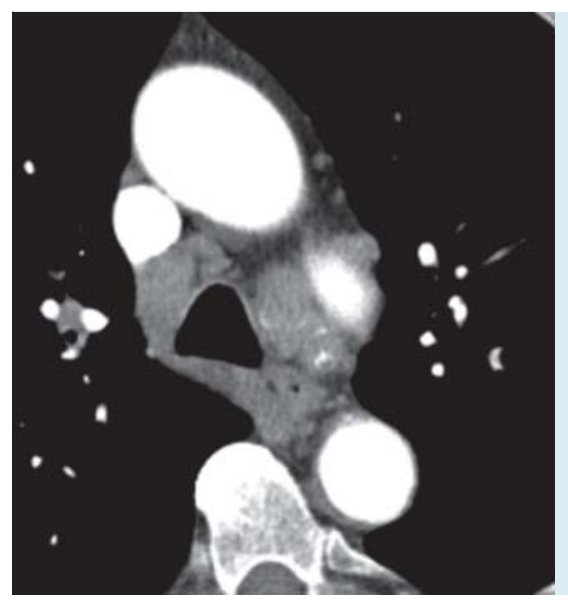

Fig. 4 Confluence of enlarged anthracotic lymph nodes in ATS region $4 \mathrm{R}$ and $4 \mathrm{~L}$; nodes in region $4 \mathrm{~L}$ show subtle calcifications.

Abb. 4 Deutlich vergrößerte konfluierende Lymphknoten der ATSRegionen $4 \mathrm{R}$ und $4 \mathrm{~L}$ bei mediastinaler Lymphknotenanthrakose. Die konfluierenden LK in der Region $4 \mathrm{~L}$ zeigen feine Verkalkungen.

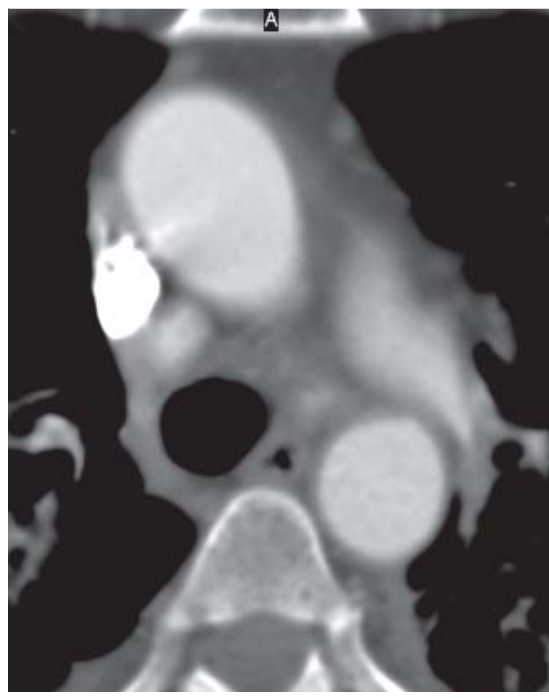

Fig. 5 Total and homogeneous hyperdensity of an enlarged mediastinal lymph node (ATS 2 R) demonstrating lymph node anthracosis in EBUS-TBNA.

Abb. 5 Diffuse Verdichtung eines vergrößerten mediastinalen Lymphknoten in der ATS-Region $2 \mathrm{R}$ auf dem Boden einer zytologisch nachgewiesenen Lymphknotenantrakose.

\section{Discussion}

Although the CT finding of enlarged mediastinal lymph nodes in cases of lung cancer is commonly interpreted as an indicator for metastatic disease, it is also seen in many benign conditions like sarcoidosis, chronic heart failure, COPD and pneumoconiosis $[1,6,12-17]$. While the occurrence of enlarged calcified mediastinal lymph nodes has been generally accepted as a sign of pneumoconiosis in coal workers [16], to date - perhaps as a result of the decline of the coal mining and steel industries in Western countries - less attention has been paid to the impact of dust on mediastinal lymph node staging in cancer patients. Thus, occupational exposure to dust was documented in only one patient in the present study. On the other hand the majority of patients with EBUS-proven mediastinal lymph node anthracosis showed bronchial wall thickening and emphysema in CT as signs of COPD or reported severe nicotine abuse. A distinct association between degree of COPD, smoking history and CT findings of anthracotic lymph nodes could not be demonstrated -at least not because of the methodological limitations of the present study. Nevertheless, the findings of the present study demonstrate that anthracosis may be found in considerably enlarged mediastinal lymph nodes up to $23 \mathrm{~mm}$ in short axis diameter. In these lymph nodes calcification was observed in approximately one third, which is in accordance with the literature [18-20]. While some authors assessed nodal confluence as a reliable indicator of malignancy [21], this finding was observed as well in nearly one third of the anthracotic lymph nodes of our study. Therefore, we think that confluence of enlarged lymph nodes cannot be interpreted as a sign of metastatic disease.

The findings of our study suggest that anthracotic lymph nodes may mimic mediastinal lymph node metastases, due to the considerable sizes and nodal confluence. Although FDG-PET has now become a standard diagnostic procedure, recent studies revealed that the diagnostic accuracy of FDG-PET in patients suffering from pneumoconiosis [22-24] is rather low and similar to that of CT [25-27].

\section{Limitations}

There were remarkable limitations to our study. Firstly, the sample size was small, preventing a generalization of our results. Secondly, the study design was retrospective and therefore some critical clinical data are missing as the history of previous pneumonias or other severe airway inflammation. Another methodicbased limitation seems to be that not all enlarged nodes present on CT could have been evaluated.

In the present study no comparison has been presented with special regard to non-benign causes of lymphadenopathy. Therefore, we can only infer that anthracosis could mimic malignancy

\begin{tabular}{|c|c|c|c|c|c|c|c|}
\hline \multicolumn{2}{|c|}{ CT finding } & $\mathbf{n}$ & age (years) & male & $\begin{array}{l}\text { smoking } \\
\text { history } \\
\text { (dependence } \\
\text { degree) }\end{array}$ & $\begin{array}{l}\text { chronic } \\
\text { bronchitis } \\
\text { (degree) }\end{array}$ & $\begin{array}{l}\text { emphysema } \\
\text { (degree) }\end{array}$ \\
\hline \multirow[t]{2}{*}{ size } & short axis & 53 & $p=0.10$ & $p=0.054$ & $p=0.46$ & $p=0.88$ & $p=0.22$ \\
\hline & long axis & 53 & $p=0.13$ & $p=0.19$ & $p=0.60$ & $p=0.39$ & $p=0.15$ \\
\hline \multicolumn{2}{|c|}{ oval shape } & 45 & $p=0.56$ & $p=0.95$ & $p=0.73$ & $p=0.60$ & $p=0.07$ \\
\hline \multicolumn{2}{|c|}{ confluence } & 17 & $p=0.14$ & $p=0.90$ & $p=0.10$ & $\begin{array}{l}p=0.04 \\
r=0.28\end{array}$ & $p=0.28$ \\
\hline \multicolumn{2}{|c|}{ calcification } & 13 & $p=0.03 r=0.29$ & $p=0.81$ & $p=0.60$ & $p=0.056$ & $p=0.62$ \\
\hline
\end{tabular}

Table 3 Correlation between CT findings in EBUS-TBNA-confirmed anthracotic lymph nodes and clinical conditions. 
from the fact that some of the anthracotic lymph nodes were enlarged on CT. Therefore, we consider our results preliminary.

\section{Conclusion \\ $\nabla$}

Enlarged anthracotic mediastinal lymph nodes show most often an oval shape and are well-defined. Nodal confluence and calcifications are frequent.

\section{Clinical relevance}

- Radiologists should be aware of mediastinal lymph node enlargement due to anthracosis.

- The majority of these lymph nodes show no calcifications.

- Lymph node confluence may be observed in nearly one third of the anthracotic lymph node.

\section{Affiliations}

${ }^{1}$ Department of Interventional and Diagnostic Radiology, Allgemeines Krankenhaus Hagen

2 Department of Medicine, Allgemeines Krankenhaus, Hagen

3 Department of Medicine, Sana Klinikum Duisburg

${ }^{4}$ Department of Pathology of the Universityhospital Duesseldorf, Heinrich Heine Universität, Duesseldorf

${ }^{5}$ Department of Diagnostic and Interventional Radiology and Nuclearmedicine, Marienhospital Herne

${ }^{6}$ Department of Radiology, Universityhospital Wuerzburg

\section{References}

1 Kirchner J, Kirchner EM, Goltz JP et al. Prevalence of enlarged mediastinal lymph nodes in heavy smokers-a comparative study. Eur Radiol 2011; 21: 1594-1599

2 Gold JA, Jagirdar J, Hay JG et al. Hut lung. A domestically acquired particulate lung disease. Medicine (Baltimore) 2000; 79: 310-317

3 Kim YJ, Jung CY, Shin HW et al. Biomass smoke induced bronchial anthracofibrosis: presenting features and clinical course. Respir Med 2009; 103: $757-765$

4 Klaaver M, Kars AH, Maat AP et al. Pseudomediastinal fibrosis caused by massive lymphadenopathy in domestically acquired particulate lung disease. Ann Diagn Pathol 2008; 12: 118-121

5 Naccache JM, Monnet I, Nunes $H$ et al. Anthracofibrosis attributed to mixed mineral dust exposure: report of three cases. Thorax 2008; 63: $655-657$

6 Hartung W, Moon JS. Current pattern of anthracosilicosis, its complications and correlation with other diseases (evaluation of 300 legal autopsies 1977-1988). Pneumologie 1992; 46: 516-524

7 Glazer GM, Gross BH, Quint LE et al. Normal mediastinal lymph nodes: number and size according to American Thoracic Society mapping. Am J Roentgenol 1985; 144: $261-265$
8 Pombo F, Rodríguez E, Mato J et al. Patterns of contrast enhancement of tuberculous lymph nodes demonstrated by computed tomography. Clin Radiol 1992; 46: 13-17

9 American Thoracic Society. Medical section of the American Lung Association. Clinical staging of primary lung cancer. Am Rev Respir Dis 1983; 127: 659-664

10 Herth FJ, Ernst A, Eberhardt $R$ et al. Endobronchial ultrasound-guided transbronchial needle aspiration of lymph nodes in the radiologically normal mediastinum. Eur Respir J 2006; 28: 910-914

11 Awadh N, Müller NL, Park CS et al. Airway wall thickness in patients with near fatal asthma and control groups: assessment with high resolution computed tomographic scanning. Thorax 1998; 53: 248-253

12 Ardekani MS, Issa M, Green L. Diagnostic and economic impact of heart failure induced mediastinal lymphadenopathy. Int J Cardiol 2006; 109: $137-138$

13 Baldwin DR, Lambert L, Pantin CF et al. Silicosis presenting as bilateral hilar lymphadenopathy. Thorax 1996; 51: 1165-1167

14 Hunt BM, Vallières E, Buduhan G et al. Sarcoidosis as a benign cause of lymphadenopathy in cancer patients. Am J Surg 2009; 197: 629-632

15 Kirchner J, Kirchner EM, Goltz JP et al. Enlarged hilar and mediastinal lymph nodes in chronic obstructive pulmonary disease. J Med Imaging Radiat Oncol 2010; 54: 333-338

16 McLoud TC. Occupational lung disease. Radiol Clin North Am 1991; 29: 931-941

17 Ooi CG, Khong PL, Cheng RS et al. The relationship between mediastinal lymph node attenuation with parenchymal lung parameters in silicosis. Int J Tuberc Lung Dis 2003; 7: 1199-1206

18 Bilici A, Erdem T, Boysan SN et al. A case of anthracosis presenting with mediastinal lymph nodes mimicking tuberculous lymphadenitis or malignancy. Eur J Intern Med 2003; 14: 444-446

19 Hartung W, Moon JS. Current pattern of anthracosilicosis, its complications and correlation with other diseases (evaluation of 300 legal autopsies 1977-1988). Pneumologie 1992; 46: 516-524

20 Vahlensieck $M$, Overlack A, Müller KM. Computed tomographic highattenuation mediastinal lymph nodes after aluminum exposition. Eur Radiol 2000; 10: 1945-1946

21 Stern WB, Silver CE, Zeifer BA et al. Computed tomography of the clinically negative neck. Head Neck 1990; 12: 109-113

22 Cheng NM, Yeh TW, Ho KC et al. False positive F-18 FDG PET/CT in neck and mediastinum lymph nodes due to anthracosis in a buccal cancer patient. Clin Nucl Med 2011; 36: 963-964

23 Reichert M, Bensadoun ES. PET imaging in patients with coal workers pneumoconiosis and suspected malignancy. J Thorac Oncol 2009; 4: 649-651

24 Saydam 0 , Gokce M, Kilicgun A et al. Accuracy of positron emission tomography in mediastinal node assessment in coal workers with lung cancer. Med Oncol 2012; 29: 589-594

25 Lin WY, Hsu WH, Lin KH et al. Role of preoperative PET-CT in assessing mediastinal and hilar lymph node status in early stage lung cancer. J Chin Med Assoc 2012; 75: $203-208$

26 Paul NS, Ley S, Metser U. Optimal imaging protocols for lung cancer staging: CT, PET, MR imaging, and the role of imaging. Radiol Clin North Am 2012; 50: 935-949

27 Yasufuku K, Nakajima T, Motoori K et al. Comparison of endobronchial ultrasound, positron emission tomography, and CT for lymph node staging of lung cancer. Chest 2006; 130: 710-718 